\title{
Assessment of free fatty acids and cholesteryl esters delivered in liposomes as novel class of antibiotic
}

\author{
Annie H. Cheung Lam ${ }^{1}$, Natalie Sandoval' ${ }^{1}$ Ritambhara Wadhwa ${ }^{1}$, Janine Gilkes ${ }^{1}$, Thai Q. Do ${ }^{2}$, William Ernst ${ }^{2}$, \\ Su-Ming Chiang ${ }^{2}$, Suzanne Kosina ${ }^{2}$, H. Howard Xu' ${ }^{1}$, Gary Fujii' ${ }^{2}$ and Edith Porter ${ }^{{ }^{*}}$
}

\begin{abstract}
Background: Healthcare associated infections (HAl) with multidrug-resistant (MDR) bacteria continue to be a global threat, highlighting an urgent need for novel antibiotics. In this study, we assessed the potential of free fatty acids and cholesteryl esters that form part of the innate host defense as novel antibacterial agents for use against MDR bacteria.

Methods: Liposomes of six different phospholipid mixtures were employed as carrier for six different fatty acids and four different cholesteryl esters. Using a modified MIC assay based on DNA quantification with the fluoroprobe Syto9, formulations were tested against Gram-positive and Gram-negative bacteria implicated in HAI. Formulations with MIC values in the low $\mu \mathrm{g} / \mathrm{mL}$ range were further subjected to determination of minimal bactericidal activity, hemolysis assay with sheep erythrocytes, and cytotoxicity testing with the human liver cell line HepG2. The potential for synergistic activity with a standard antibiotic was also probed.

Results: Palmitic acid and stearic acid prepared in carrier 4 (PA4 and SA4, respectively) were identified as most active lipids (MIC against MDR Staphylococcus epidermidis was 0.5 and $0.25 \mu \mathrm{g} / \mathrm{mL}$, respectively; MIC against vancomycin resistant Enterococcus faecalis (VRE) was 2 and $0.5 \mu \mathrm{g} / \mathrm{mL}$, respectively). Cholesteryl linoleate formulated with carrier 3 (CL3) exhibited activity against the S. epidermidis strain (MIC $1 \mu \mathrm{g} / \mathrm{mL}$ ) and a Pseudomonas aeruginosa strain (MIC $8 \mu \mathrm{g} /$ $\mathrm{mL}$ ) and lowered the vancomycin MIC for VRE from 32-64 $\mu \mathrm{g} / \mathrm{mL}$ to as low as $4 \mu \mathrm{g} / \mathrm{mL}$. At $90 \mu \mathrm{g} / \mathrm{mL}$ PA4, SA4, and CL3 effected less than $5 \%$ hemolysis over $3 \mathrm{~h}$ and PA4 and CL3 did not exhibit significant cytotoxic activity against HepG2 cells when applied at $100 \mu \mathrm{g} / \mathrm{mL}$ over $48 \mathrm{~h}$.
\end{abstract}

Conclusions: Our results showed that selected fatty acids and cholesteryl esters packaged with phospholipids exhibit antibacterial activity against Gram-positive and Gram-negative bacteria and may augment the activity of antibiotics. Bactericidal activity could be unlinked from hemolytic and cytotoxic activity and the type of phospholipid carrier greatly influenced the activity. Thus, fatty acids and cholesteryl esters packaged in liposomes may have potential as novel lipophilic antimicrobial agents.

Keywords: Antibiotic, Antimicrobial lipids, Drug delivery, Liposomes, Multidrug-resistance, HAl, Innate immunity

\section{Background}

Healthcare associated infections (HAI) are one of the leading causes of preventable deaths in the US, and present a significant economic burden in healthcare costs.

\footnotetext{
*Correspondence: eporter@calstatela.edu

1 Department of Biological Sciences, California State University Los

Angeles, 5151 State University Drive, Los Angeles, CA 90032, USA

Full list of author information is available at the end of the article
}

Warnings regarding infectious agents developing into multidrug-resistant forms and the possibility of future pandemic outbreaks have been repeatedly issued by the Centers for Disease Control and Prevention and the World Health Organization. The global dissemination of drug resistant carbapenemase-producing Enterobacteriaceae in the healthcare setting [1] is just one of the more recent examples. Other causes of HAI with multidrug-resistant bacteria include methicillin-resistant 
Staphylococcus aureus (MRSA), vancomycin-resistant Enterococcus faecalis (VRE), Pseudomonas aeruginosa, and Acinetobacter baumannii [2]. Multidrug-resistant Staphylococcus epidermidis has become notorious for catheter associated infections. Nationwide, at least one case of HAI occurs for every 25 patients [3]. Despite some progress in containing the occurrence of HAI through infection control measures [4], an urgent need for the development of novel antibacterial agents remains. No new class of antibiotic has been discovered since 1987 and the last six approved new drugs are all modifications of existing drugs [5, 6]. Drug discovery through target-focused screening of large libraries of synthetic compounds has failed with a major reason being insufficient compound penetration into the microbial cell [7], and transition of natural antimicrobial peptides to the clinical market has proven to be difficult $[8,9]$. Ongoing efforts include antisense RNA targeting essential microbial genes [10] and exploitations of uncultured bacteria [11]. However, host derived lipids, increasingly recognized as important antimicrobial effectors of the innate host defense [12, 13], might also be exploited for novel drug design.

Lipids are a widely heterogeneous group of molecules that share hydrophobic or mixed hydrophobic/hydrophilic properties [14]. The major lipid classes include: fatty acids- the basic building blocks for more complex lipids, cholesteryl esters, and phospholipids. Cholesteryl esters are formed through esterification of a fatty acid to cholesterol. Phospholipids typically consist of a glycerol with two fatty acid residues attached, a phosphate group and additions such as choline, an alcohol, or amines. The antimicrobial activity of fatty acids has been known for some time (reviewed in [15]) while antimicrobial properties of cholesteryl esters have been more recently discovered [16].

Motivated by the urgent need for novel antibacterial strategies, the main objective for this study was to examine whether lipids identified as antibacterial effectors in body fluids may have a potential to be used in innovative drug design. Due to their inherent hydrophobicity, lipids require carriers in aqueous environments. Liposomes have been used in the past for delivery of compounds with hydrophobic properties [17] offering in some cases the benefit of reducing cytotoxicity [18]. Liposomes are phospholipid vesicles where the polar head groups of phospholipids interact with the aqueous outer environment and the fatty acid tails provide a hydrophobic environment for lipophilic compounds. When used as carrier, liposomes also provide the advantage of allowing incorporation of tags for targeted delivery $[19,20]$.

\section{Methods}

\section{Bacterial strains}

The following strains were purchased from American Type Culture Collection (ATCC, Manassas, VA, multidrug-resistant S. epidermidis ATCC 700566, methicillin resistant S. aureus ATCC 33591 (MRSA), vancomycin resistant E. faecalis ATCC 700802 (VRE), E. cloacae ATCC 49141, P. aeruginosa ATCC 9027, and A. baumanii ATCC 19606. In addition, a clinical cystic fibrosis isolate of $P$. aeruginosa (PACF, Welsh laboratory, University of Iowa; also described in [16]) was used. Stock cultures were stored at $-80{ }^{\circ} \mathrm{C}$ using the CryoSaver system (Hardy Diagnostics, Santa Maria, CA). For each assay, isolated colonies subcultured from freshly thawed bacteria were used to inoculate the ATCC recommended broth media purchased from Becton, Dickinson, and Company (BD, Franklin Lakes, NJ; nutrient broth for MRSA and A. baumannii, brain heart infusion for VRE, tryptic soy broth for the remainder). After overnight culture at $37^{\circ} \mathrm{C}$ (20-24 h for A. baumannii, 16-18 h for others) bacteria were adjusted to McFarland 0.5 in $140 \mathrm{mM} \mathrm{NaCl}$, diluted 100-fold, and inoculated into 1.1-fold concentrated cation-adjusted Mueller-Hinton broth (MHB+, Teknova, Hollister, CA) to yield $5 \times 10^{5} \mathrm{CFU} / \mathrm{mL}$.

\section{Antibiotics}

Oxacillin, cefotaxime, vancomycin, tetracycline, and ciprofloxacin were purchased from Sigma-Aldrich in salt form, dissolved in $\mathrm{dH}_{2} \mathrm{O}$, and kept as stock solution $(10 \mathrm{mg} / \mathrm{mL})$ at $-20^{\circ} \mathrm{C}$.

\section{Lipids}

Lipids investigated (test lipids, Table 1) included free fatty acids (palmitic, stearic, oleic, linoleic, arachidonic, and docosahexaenoic acid) and cholesteryl esters (cholesteryl palmitate, -oleate, -linoleate, and -arachidonate) and were purchased from Sigma-Aldrich, St. Louis, MO. Carrier lipids included phospholipids and cholesterol. The phospholipids 1,2-dimyristoyl-sn-glycero-3-phosphatidylcholine (DMPC), 1,2-dipalmitoyl-snglycero-3-phosphocholine (DPPC), 1,2-distearoyl-sn-glycero-3-phosphatidyl-(10-rac-glycerol) (DSPG), and Hydrogenated Soy Phosphatidylcholine (HSPC; SPC-3) were purchased from Lipoid $\mathrm{GmbH}$, Ludwigshafen, Germany. The phospholipid 1,2-dimyristoyl-sn-glycero-3-phosphatidyl-(10-rac-glycerol) (DMPG) was purchased from Nippon Fine Chemical, Osaka, Japan, and cholesterol from NOF Corporation, Tokyo, Japan.

\section{Liposome preparation}

Six different carrier liposome formulations (carrier-1-6) were generated using the phospholipids and cholesterol 
Table 1 Lipids investigated in this study

\begin{tabular}{llllll}
\hline Lipid class & Test lipid & Code & Molecular formula & Molecular weight $^{\mathbf{a}}$ & Double bonds $^{\mathbf{b}}$ \\
\hline Free fatty acids & Palmitic acid & $\mathrm{PA}$ & $\mathrm{C}_{16} \mathrm{H}_{32} \mathrm{O}_{2}$ & 256.42 & 0 \\
& Stearic acid & $\mathrm{SA}$ & $\mathrm{C}_{18} \mathrm{H}_{36} \mathrm{O}_{2}$ & 284.48 & 0 \\
& Oleic acid & $\mathrm{OA}$ & $\mathrm{C}_{18} \mathrm{H}_{34} \mathrm{O}_{2}$ & 282.46 & 1 \\
& Linoleic acid & $\mathrm{LA}$ & $\mathrm{C}_{18} \mathrm{H}_{32} \mathrm{O}_{2}$ & 280.45 & 2 \\
& Arachidonic acid & $\mathrm{AA}$ & $\mathrm{C}_{20} \mathrm{H}_{32} \mathrm{O}_{2}$ & 304.47 & 4 \\
& Docosahexaenoic acid & $\mathrm{DA}$ & $\mathrm{C}_{22} \mathrm{H}_{32} \mathrm{O}_{2}$ & 328.49 & 6 \\
\multirow{3}{*}{ Cholesteryl esters } & Cholesteryl palmitate & $\mathrm{CP}$ & $\mathrm{C}_{43} \mathrm{H}_{76} \mathrm{O}_{2}$ & 625.06 & 0 \\
& Cholesteryl oleate & $\mathrm{CO}$ & $\mathrm{C}_{45} \mathrm{H}_{78} \mathrm{O}_{2}$ & 651.10 & 1 \\
& Cholesteryl linoleate & $\mathrm{CL}$ & $\mathrm{C}_{45} \mathrm{H}_{76} \mathrm{O}_{2}$ & 649.08 & 2 \\
& Cholesteryl arachidonate & $\mathrm{CA}$ & $\mathrm{C}_{47} \mathrm{H}_{76} \mathrm{O}_{2}$ & 673.11 & 4 \\
\hline
\end{tabular}

a As provided by the manufacturer

b Number of unsaturated double bonds in the free or esterified fatty acid

listed above (carrier 1: HSPC; carrier 2: DPPC; carrier 3: DMPC; carrier 4: HSPC:DSPG [0.75:0.5]; carrier 5: DPPC:cholesterol [0.8:0.05]; carrier 6: HSPC:cholesterol [0.70:0.10], all in molar ratios). Principles of the liposome preparation have been described more in detail earlier [21]. Liposomes were prepared by dissolving the carrier and test lipids (0.8:0.2, respectively) in chloroform/ methanol $(1: 1 v / v)$. The organic solvents were evaporated under a stream of nitrogen gas at $65^{\circ} \mathrm{C}$, and residual solvent removed in vacuo for $>24 \mathrm{~h}$. Unilamellar liposomes were formed by hydrating the lipid films with $9 \%$ sucrose and probe sonicating until translucent. The liposomes were then sterilized by passage through a $0.22 \mu \mathrm{m}$ filter. Each liposome preparation was characterized by dynamic light scattering (UPA 150, Microtrac, Montgomeryville, PA; see Additional file 1: Table S1). Liposomes were stored in $9 \%$ sucrose at $1 \mathrm{mg} / \mathrm{mL}$ test lipid (5-10 mg total lipid $/ \mathrm{mL}$ ) for up to 6 month at $4{ }^{\circ} \mathrm{C}$. As a control $9 \%$ sucrose was used. When necessary, liposomal formulations containing test lipids were diluted with $9 \%$ sucrose to ten-fold concentrated working stocks. Stock solutions for the respective carrier liposomes without test lipids were diluted so that the phospholipid concentration was the same as the phospholipid concentration in the formulations with test lipid.

\section{Determination of minimal inhibitory concentration (MIC)} Following Clinical and Laboratory Standards Institute M07-A9 for broth microdilution assay [22], $10 \mu \mathrm{L}$ aliquots of serially diluted 10 -fold concentrated antibiotic were added to general assay 96 well- round bottom polystyrene microtiter plates followed by the addition of $90 \mu \mathrm{L}$ of diluted bacteria as prepared in above. For sterility control, 1.1-fold cation-adjusted Mueller-Hinton broth $(\mathrm{MHB}+)$ without bacteria was included in the testing. The plates were then incubated at $37^{\circ} \mathrm{C}$ for $16-24 \mathrm{~h}$, as recommended, in air and turbidity was read at $650 \mathrm{~nm}$. MIC was the lowest concentration of antibiotic that prevented growth reflected in measurable turbidity.

\section{Modified minimal inhibitory concentration assay}

Due to the inherent turbidity of the liposomal formulations interfering with absorbance readings, the MIC protocol was modified; after completion of the MIC assay the DNA content was quantified with the fluoroprobe Syto9 (Invitrogen, Carlsbad, CA). Syto9 freely crosses cell membranes and binds to DNA upon which green fluorescence is emitted. The degree of fluorescence correlates with the amount of DNA, thus with the bacterial concentration in a sample, regardless of sample turbidity contributed by the liposomal formulations [16]. Using black untreated 96 well microtiter plates with clear flat bottom wells (Costar, Corning Life Sciences, Union City, CA) bacteria were otherwise prepared, mixed with antibiotics or liposomes, and incubated according to the standard MIC procedure. Each assay included a growth control (incubation of bacteria in $\mathrm{MHB}+$ ) and a killing control (incubation of bacteria with effective antibiotic). In addition, liposomes and antibiotics were incubated in the absence of bacteria to control for sterility of the reagents and to obtain background fluorescence readings. At the end of the incubation period, $100 \mu \mathrm{L}$ of $1.25 \mu \mathrm{M}$ Syto9 (diluted in $\mathrm{dH}_{2} \mathrm{O}$ ) was added to each well. After 15 min incubation at RT in the dark, relative fluorescence units (RFU) were measured (485 nm ex $/ 530 \mathrm{~nm}_{\mathrm{em}}$; Tecan GENios, Tecan Systems, Inc., San Jose, CA). RFUs obtained from liposomal formulations or antibiotic incubated in medium without bacteria (background fluorescence) were subtracted from the RFUs obtained from corresponding wells with bacteria present. All liposomal formulations were first screened at $64 \mu \mathrm{g} / \mathrm{mL}$ test lipid. Those formulations that, compared to untreated bacteria, 
effected at least $95 \%$ reduction of RFUs of at least two different bacterial strains were further investigated. They were subjected to serial dilution and determination of modified MIC. Modified MIC was defined as the lowest concentration of liposomal formulation that produced RFUs at background level.

\section{Determination of minimal bactericidal concentration (MBC)}

After completion of the MIC assay, $6 \mu \mathrm{L}$ of each well was serially diluted and spot plated. Based on Clinical and Laboratory Standards Institute guidelines M26-A [23], concentrations of liposomal formulations that reduced growth to less than 15 colony forming units $(\mathrm{CFU}) / 6 \mu \mathrm{L}$ or $2500 \mathrm{CFU} / \mathrm{mL}$ were considered bactericidal.

\section{Vancomycin synergism}

The protocol for the modified MIC assay was employed with the following changes: instead of $10 \mu \mathrm{L}$ of tenfold concentrated antibiotic or test lipid, $5 \mu \mathrm{L}$ of 20 -fold concentrated antibiotic and $5 \mu \mathrm{L}$ of 20 -fold concentrated test lipid was used. First, the MIC of vancomycin applied alone was established for VRE and then, serially diluted vancomycin was tested in the presence and absence of $5 \mu \mathrm{g} / \mathrm{mL}$ cholesteryl linoleate in carrier 3 .

\section{Hemolytic activity testing}

Sheep red blood cells (RBCs) at $50 \% v / v$ whole blood in Alsever's solution (Sigma-Aldrich) were washed by repeated centrifugation at $500 \times g$ and resuspension in saline $(0.9 \% \mathrm{w} / \mathrm{v})$ until the absorbance of supernatant at $405 \mathrm{~nm}$ equaled the absorbance of saline. On the final wash, RBCs were adjusted to $15 \%$ packed cell volume in normal saline (15 parts sedimented RBC plus 85 parts saline). In microplates, $10 \mu \mathrm{L}$ of this was then added to $90 \mu \mathrm{L}$ liposomal formulations or carrier which had been diluted in saline to the desired test concentration. As negative control, RBCs were mixed with saline. To obtain maximal (100 \%) hemolysis, Triton X-100 (Fisher Scientific) was added to $1 \%$ final concentration. Samples were then incubated at $37^{\circ} \mathrm{C}, 7.5 \% \mathrm{CO}_{2}$ for up to $24 \mathrm{~h}$. At the end of each incubation period ( $30 \mathrm{~min}, 3 \mathrm{~h}$, and $24 \mathrm{~h}$ ), the percent hemolysis was estimated by the quantification of liberated hemoglobin by absorbance reading. To prevent errors due to liposomal components affecting the oxidation state of the hemoglobin (and thus the absorbance reading) and to dissociate all major hemoglobins from other sample components (also affecting the absorbance reading), all hemoglobin species were converted to hematin based on the Alkaline Hematin Detergent-575 method [24]. Briefly, intact cells were pelleted by centrifugation at $4500 \times g$ and the resulting supernatants were diluted to $50 \% v / v$ in $1 \%$ Triton-X-100/0.5 M NaOH.
Absorbance at $405 \mathrm{~nm}$ (Soret band) was measured in a Multiskan Ascent plate reader. After blanking with $50 \%$ saline $v / v$ in $1 \%$ Triton $\mathrm{X}-100 / 0.5 \mathrm{M} \mathrm{NaOH}$, the percent hemolysis was calculated, as follows: $\% \mathrm{H}=$ (absorbance of treatment sample/absorbance of $100 \%$ hemolysis sample) $\times 100$.

\section{Cytotoxicity testing}

Cytotoxic activity of liposomal formulations was assessed with a hepatic cell line that is commonly used for this purpose [25]. HepG2 cells (ATCC, Manassas, VA) were maintained in Dulbecco's Modified Eagle Medium (DMEM) supplemented with $10 \%$ fetal bovine serum, $1000 \mathrm{IU} / \mathrm{mL}$ penicillin, $100 \mu \mathrm{g} / \mathrm{mL}$ streptomycin and $2 \mathrm{mM}$ L-glutamine (Invitrogen, Carlsbad, CA) in tissue culture flasks at $37{ }^{\circ} \mathrm{C}$ with $5 \% \mathrm{CO}_{2}$. Assays were performed in 96-well flat bottom tissue culture treated plates (Corning, Cambridge, MA). For passing, cells grown to $80 \%$ confluency were detached with $0.25 \%$ trypsin/0.53 mM EDTA (Cellgro, Mediatech, Inc, Manassas, VA) for $3 \mathrm{~min}$, centrifuged at $1000 \times g$ for $8 \mathrm{~min}$ at $23{ }^{\circ} \mathrm{C}$, and after resuspension in culture medium split at a ratio of 1: 4. For experiment seeding, cells were detached and spun as above, adjusted to $5 \times 10^{5}$ viable cells $/ \mathrm{mL}$, and aliquoted at $100 \mu \mathrm{L}$ per well. After incubation for 18-24 h, until $80 \%$ confluency had been reached, supernatants were removed and replaced with $100 \mu \mathrm{L}$ of liposome treatment (liposomal formulations in $9 \%$ sucrose at $1000 \mu \mathrm{g} / \mathrm{mL}$ test lipid further diluted 1:10 in culture medium to yield a final concentration of $100 \mu \mathrm{g} / \mathrm{mL}$ test lipid). Stocks for carrier liposomes were diluted so that their phospholipid concentration was the same as the phospholipid concentration of the test lipid in its respective formulation. As negative control, $9 \%$ sucrose diluted 1:10 in culture medium was used. After $48 \mathrm{~h}$ incubation at $37{ }^{\circ} \mathrm{C}$ with $5 \% \mathrm{CO}_{2}$ cell viability was determined with the XTT assay (Roche Diagnostics Pleasanton, CA) according to the manufacturer's instructions. Previously untreated cells that were incubated for 15 min with $0.1 \%$ Triton X 100 immediately prior to the XTT assay were used as positive control for cytotoxicity. Cytotoxic activity of lipids was quantified based on the inhibition of cell proliferation after lipid treatment relative to untreated cells.

\section{Data analysis}

MIC and MBC assays were conducted in duplicates and repeated at least once. Hemolysis assays were performed in triplicate and cytotoxicity assays were conducted in replicates of four and repeated for a total of three independent experiments. Microsoft Excel 2013 was used for raw data analysis and graphing. IBM SPSS Statistics version 20 was used for statistical analysis. 


\section{Results}

\section{Validation of modified MIC assay with fluorescence readout}

Due to their hydrophobicity- in particular cholesteryl esters cannot be dissolved in aqueous media- test lipids were incorporated into carrier liposomes. Six different formulations designated as carrier 1-6 were tested. The particulate nature of liposomes interferes with turbidity readings which are routinely used in standard MIC assays to evaluate bacterial growth in the presence and absence of antibiotics. Therefore, in this study, we employed a modified antimicrobial susceptibility testing assay that utilizes the green fluorescent DNA probe Syto9 to quantify bacterial proliferation [16]. As summarized in Table 2, the modified assay with fluorescence readout produces MICs that were mostly comparable to those determined with standard MIC testing, with both sets of MIC values within acceptable ranges as defined by the Clinical and Laboratory Standards Institute.

\section{Spectrum of activity of liposomal formulations}

First, all formulations were screened at $64 \mu \mathrm{g} / \mathrm{mL}$ test lipid (free fatty acids or cholesteryl esters) against bacterial strains that cause HAI and are resistant to multiple antibiotics (Table 3). For comparison, a $P$. aeruginosa strain previously reported to be susceptible to cholesteryl esters (PACF, [16]) was also used. When test lipids were serially diluted, the corresponding carrier lipids were similarly diluted maintaining the ratio of test lipid to carrier lipid. For each test lipid the corresponding carrier formulation itself was also assayed at the equivalent concentration. Of note, the liposome size was influenced by the lipid species (see Additional file 1: Table S1).

Based on an at least $80 \%$ inhibition threshold, overall, test liposomes were more effective against the Gram-positive strains tested than the Gram-negative strains. Among the Gram-positive bacteria tested, S. epidermidis and VRE were inhibited by several formulations representing both fatty acids, in particular PA4 and SA4, and cholesteryl esters (CL3 and CA4 for S. epidermidis and VRE, respectively). Among the Gram-negative bacteria tested, one of the two $P$. aeruginosa strains and the $A$. baumannii strain were completely resistant to all lipids tested. Furthermore, the E. cloacae strain was inhibited only by two fatty acid formulations (LA4, AA4) and one cholesteryl ester formulation (CL3). However, the cystic fibrosis isolate of $P$. aeruginosa exhibited broad susceptibility to several fatty acid and cholesteryl ester formulations suggesting that there is a strain dependent susceptibility. In general, test lipids prepared with carrier 3 and carrier 4 demonstrated the greatest activity. There was also some inhibitory activity of the carrier lipids independent from the presence of fatty acids or cholesteryl esters (see Table 3 ).

Those test lipid formulations that effected at least $95 \%$ growth inhibition against at least two different bacterial strains in the screening assay were further subjected to determination of minimal inhibitory concentration (Table 4). The lowest MIC values were determined for

Table 2 Validation of the modified antimicrobial susceptibility testing assay employing the DNA binding fluoroprobe Syto9

\begin{tabular}{|c|c|c|c|c|}
\hline \multirow[t]{3}{*}{ Strains $^{a}$} & \multirow[t]{3}{*}{ Antibiotic } & \multicolumn{3}{|c|}{$\operatorname{MIC}(\mu \mathrm{g} / \mathrm{mL})^{\mathrm{b}}$} \\
\hline & & \multirow[t]{2}{*}{ Expected $^{\mathbf{c}}$} & \multicolumn{2}{|l|}{ Measured } \\
\hline & & & Standard assay & Modified assay \\
\hline \multirow[t]{4}{*}{ S. aureus ATCC 29213} & Oxacillin & $0.12-0.5$ & 0.0625 & 0.5 \\
\hline & Cefotaxime & $1-4$ & $1-2$ & 2 \\
\hline & Tetracycline & $0.12-1$ & $0.125-0.25$ & 0.5 \\
\hline & Ciprofloxacin & $0.12-0.5$ & $0.25-0.5$ & 0.5 \\
\hline \multirow[t]{3}{*}{ E. faecalis ATCC 29212} & Oxacillin & $8-32$ & $0.5-2$ & $8-16$ \\
\hline & Tetracycline & $8-32$ & 16 & 16 \\
\hline & Ciprofloxacin & $0.25-1$ & $0.5-1$ & 2 \\
\hline \multirow[t]{3}{*}{ E. coli ATCC 25922} & Cefotaxime & $0.03-0.12$ & 0.125 & 0.125 \\
\hline & Tetracycline & $0.5-2$ & 1 & $2-4$ \\
\hline & Ciprofloxacin & $0.004-0.015$ & 0.0156 & 0.0156 \\
\hline \multirow[t]{3}{*}{ P. aeruginosa ATCC 27853} & Cefotaxime & $8-32$ & 8 & 16 \\
\hline & Tetracycline & $8-32$ & 16 & $16-32$ \\
\hline & Ciprofloxacin & $0.25-1$ & 0.25 & $0.5-1$ \\
\hline
\end{tabular}

\footnotetext{
a Designated ATCC quality control strains for antimicrobial susceptibility testing

b Shown are the values derived from two independent experiments each conducted in triplicate

c According to Clinical and Laboratory Standards Institute M100-S22 for broth microdilution assay
} 
Table 3 Screening of liposomal formulations for antibacterial activity

\begin{tabular}{|c|c|c|c|c|c|c|c|c|c|c|c|c|c|c|}
\hline \multirow[t]{2}{*}{ ID } & \multicolumn{2}{|l|}{ SE } & \multicolumn{2}{|c|}{ MRSA } & \multicolumn{2}{|l|}{ VRE } & \multicolumn{2}{|l|}{ ENC } & \multicolumn{2}{|l|}{ PACF } & \multicolumn{2}{|l|}{ PA } & \multicolumn{2}{|l|}{$A B$} \\
\hline & TL & CR & $\mathrm{TL}$ & $\mathrm{CR}$ & TL & CR & TL & CR & $\mathrm{TL}$ & CR & $\mathrm{TL}$ & CR & TL & $\mathrm{CR}$ \\
\hline PA1 & 64 & -11 & 62 & 75 & 53 & -89 & -14 & -80 & 4 & 32 & 20 & 13 & 23 & -93 \\
\hline PA3 & 67 & 3 & 69 & 82 & 99 & -63 & 14 & -56 & 84 & 92 & 28 & 5 & 0 & -91 \\
\hline PA4 & 100 & 8 & 32 & 62 & 99 & -90 & -10 & 6 & 3 & 15 & 41 & 45 & 35 & -59 \\
\hline PA6 & 66 & -11 & 42 & 59 & 65 & -85 & 7 & -48 & 12 & 34 & -17 & -22 & 46 & -58 \\
\hline SA1 & 15 & -14 & 63 & 63 & -76 & -91 & 22 & -72 & 0 & 10 & -7 & 18 & 28 & -76 \\
\hline SA3 & -28 & -8 & 64 & 72 & 83 & -78 & 22 & -93 & 70 & 93 & 27 & 7 & 26 & -60 \\
\hline SA4 & 100 & 7 & 38 & 64 & 100 & -99 & -18 & -11 & 12 & 19 & 44 & 47 & 31 & -63 \\
\hline SA6 & 5 & -61 & 46 & 50 & -25 & -86 & -30 & -143 & -16 & 27 & -22 & -25 & 29 & -81 \\
\hline OA1 & 32 & -21 & 62 & 79 & 40 & -142 & 56 & -60 & 22 & 38 & -1 & 8 & 17 & -77 \\
\hline OA3 & 50 & -49 & 80 & 83 & 50 & -41 & -66 & -117 & 87 & 93 & -9 & 4 & 14 & -92 \\
\hline OA4 & 31 & -26 & 59 & 79 & 55 & -58 & -7 & -25 & 12 & 17 & 52 & 45 & 31 & -84 \\
\hline OA6 & -10 & 0 & 66 & 59 & -12 & -18 & 44 & 30 & 11 & 25 & -25 & -21 & 1 & -72 \\
\hline LA1 & 5 & -27 & 49 & 70 & 25 & -156 & -31 & -121 & 8 & 46 & -6 & 12 & 18 & -70 \\
\hline LA3 & 100 & -57 & 55 & 83 & 18 & -62 & -37 & -399 & 97 & 93 & 12 & 1 & 29 & -61 \\
\hline LA4 & 86 & -32 & 60 & 79 & 94 & -101 & 89 & -103 & 10 & 20 & 5 & 45 & 0 & -75 \\
\hline LA6 & 9 & -37 & 45 & 57 & 45 & -156 & -140 & -135 & 2 & 25 & -34 & -26 & 22 & -81 \\
\hline $\mathrm{AA} 1$ & -37 & 51 & 48 & 73 & 66 & -14 & 79 & 34 & -1 & 44 & -5 & 6 & 31 & -85 \\
\hline AA3 & 72 & 94 & 50 & 82 & -8 & -40 & -6 & 8 & 91 & 94 & -17 & -8 & 34 & -57 \\
\hline AA4 & 65 & 36 & 85 & 84 & 89 & 43 & 95 & 54 & 15 & 18 & 51 & 47 & 33 & -55 \\
\hline AA6 & 45 & -69 & 45 & 58 & 33 & -91 & -1 & -131 & -8 & 14 & -29 & -20 & 34 & -55 \\
\hline $\mathrm{DA} 1$ & 22 & 2 & 72 & -42 & -10 & -11 & 34 & 42 & 38 & -90 & 19 & -91 & -1 & -76 \\
\hline DA3 & -34 & 42 & 55 & 95 & 98 & -105 & 35 & 15 & 71 & 94 & -9 & 10 & 24 & -77 \\
\hline DA4 & 15 & 1 & 28 & 54 & -29 & 44 & 11 & 80 & 18 & 36 & 14 & 30 & 5 & -67 \\
\hline DA6 & 10 & 18 & 44 & 55 & -11 & -40 & -13 & -14 & -18 & 28 & -32 & -13 & 9 & -71 \\
\hline CP1 & 85 & 99 & 74 & 74 & -14 & -7 & 36 & 70 & 27 & 43 & -10 & -19 & 21 & -83 \\
\hline $\mathrm{CP} 2$ & 71 & 100 & 67 & 74 & -15 & 3 & 15 & 9 & 87 & 66 & -5 & -6 & 15 & -90 \\
\hline CP3 & 77 & 99 & 42 & 54 & -44 & 5 & 5 & 39 & 86 & 86 & 24 & 28 & 4 & -87 \\
\hline CP5 & 62 & 100 & 65 & 71 & -6 & 7 & 9 & 58 & 82 & 63 & -19 & -9 & 15 & -75 \\
\hline $\mathrm{CO} 1$ & 19 & 43 & 53 & 57 & -11 & -26 & 29 & 24 & 34 & 20 & -9 & -5 & 24 & -69 \\
\hline $\mathrm{CO} 3$ & 10 & 100 & 59 & 70 & 62 & -6 & -34 & -22 & 99 & 95 & -25 & -18 & 4 & -78 \\
\hline $\mathrm{CO} 4$ & -20 & 14 & 38 & 90 & 84 & 16 & 29 & 29 & 12 & 18 & 11 & 50 & 35 & -56 \\
\hline CL1 & NT & NT & 64 & 67 & NT & NT & NT & NT & 95 & 72 & -41 & -26 & NT & NT \\
\hline CL3 & 100 & 52 & 65 & 47 & 21 & -39 & 94 & 36 & 100 & 88 & 45 & 23 & 16 & -82 \\
\hline $\mathrm{CL} 4$ & NT & NT & 80 & 68 & NT & NT & NT & NT & 84 & 33 & -22 & 0 & NT & NT \\
\hline $\mathrm{CA} 1$ & 74 & 10 & 59 & 54 & -16 & -27 & 45 & 29 & 82 & 24 & 11 & -4 & 19 & -70 \\
\hline CA3 & -44 & 11 & 60 & 65 & 11 & -43 & 50 & 19 & 100 & 93 & -20 & -24 & 24 & -72 \\
\hline CA4 & 53 & 94 & 53 & 87 & 31 & 100 & 47 & -1 & 72 & 25 & 8 & 42 & 13 & -68 \\
\hline
\end{tabular}

Test lipids (see Table 1 for abbreviations) prepared in carrier liposomes formulations \#1-6 with unique phospholipid composition (TL) and carrier liposomes without test lipid (CR) were screened against bacterial strains relevant to healthcare associated infections (SE multidrug-resistant Staphylococcus epidermidis ATCC 700566, MRSA methicillin resistant Staphylococcus aureus ATCC 33591, VRE vancomycin resistant Enterococcus faecalis ATCC 700802, ENC Enterococcus cloacae ATCC 49141, PA Pseudomonas aeruginosa ATCC 9027, PACF Pseudomonas aeruginosa, cystic fibrosis isolate [16], AB Acinetobacter baumanii ATCC 19606). All test lipids where employed at $64 \mu \mathrm{g} / \mathrm{mL}$. The corresponding carrier lipid concentrations were about 10-12 times higher for fatty acid formulations and 4-5 times higher for cholesteryl ester formulations. Bacterial growth was quantified based on relative fluorescence units (RFU) of the DNA probe Syto 9. Italics 80-95 \% growth inhibition; Bolded and in italics $>95 \%$ growth inhibition. Data represent means of the \% inhibition compared to untreated bacteria from two independent experiments conducted each in triplicate. ID Liposome identification, for example PA1 stands for palmitic acid prepared in carrier liposomes \# 1

$N T$ not tested

formulations PA4, SA4, and CL3 for S. epidermidis and VRE. The MIC for PA4 was $0.5 \mu \mathrm{g} / \mathrm{mL}$ against $S$. epidermidis and $2 \mu \mathrm{g} / \mathrm{mL}$ against VRE. The MIC for SA4 was
$0.25 \mu \mathrm{g} / \mathrm{mL}$ against $S$. epidermidis and $0.5 \mu \mathrm{g} / \mathrm{mL}$ against VRE. For CL3 the MIC was $1 \mu \mathrm{g} / \mathrm{mL}$ against S. epidermidis and $8 \mu \mathrm{g} / \mathrm{mL}$ against $P A C F$. The activity of LA3 
Table 4 Minimal inhibitory concentrations (MIC, given in $\mu \mathrm{g} / \mathrm{mL}$ ) of test lipids that effected a growth inhibition of $>95 \%$ against at least two different bacterial strains in the screening assay

\begin{tabular}{llll}
\hline Liposomal formulation $^{\mathbf{a}}$ & \multicolumn{4}{l}{ Bacterial strain $^{\mathbf{b}}$} \\
\cline { 2 - 4 } & SE & VRE & PACF \\
\hline PA4 & 0.50 & 2 & NT \\
SA4 & 0.25 & 0.50 & NT \\
LA3 & 64 & NT & $>64$ \\
CL3 & 1 & NT & 8 \\
\hline
\end{tabular}

Shown are MIC values derived from two independent experiments each performed in triplicate. NT not tested because not susceptible in the screening assay

a See Table 1 for letter abbreviations; numbers indicate the type of liposomal formulation used

b SE multidrug-resistant Staphylococcus epidermidis ATCC 700566, VRE vancomycin resistant Enterococcus faecalis ATCC 700802, PACF Pseudomonas aeruginosa, cystic fibrosis isolate

against PACF in the screening assay was not confirmed by the MIC assay.

\section{Bactericidal activity of selected liposomal formulations}

The liposomal formulations PA4, SA4 and CL3 were then subjected to testing for minimal bactericidal concentration (MBC) against S. epidermidis (Fig. 1). PA4 and SA4 demonstrated strong bactericidal activity (MBC of 0.5 and $0.25 \mu \mathrm{g} / \mathrm{mL}$, respectively). In contrast, CL3 was not bactericidal at the tested concentrations, reducing the bacterial inoculum by no more than $75 \%$.

\section{Effect of liposomes on vancomycin susceptibility}

To address whether antimicrobial lipids in liposomal formulation may have the potential to augment the effects of standard antibiotics, MIC of vancomycin was determined for VRE in the presence and absence of CL3, which alone-or its carrier liposomes-did not effect a substantial growth inhibition (see Table 3), or carrier liposomes. The MIC of vancomycin against VRE shifted from $64-32 \mu \mathrm{g} / \mathrm{mL}$ to as low as $4 \mu \mathrm{g} / \mathrm{mL}$ in the presence of $5 \mu \mathrm{g} / \mathrm{mL}$ CL3 (Fig. 2), which would be consistent with a shift from vancomycin resistant to susceptible, according to CLSI-M100-S22. This suggests that liposomal lipids may potentiate or restore the efficacy of antibiotics against multidrug-resistant bacteria.

\section{Hemolytic and cytotoxic activity of selected liposomal formulations}

Prior to considering clinical use, a candidate compound must be evaluated for hemolytic and cytotoxic activity. PA4, SA4, and CL3 were subjected to hemolysis testing (Table 5) and cytotoxicity testing (Fig. 3). At high dose $(900 \mu \mathrm{g} /$ $\mathrm{mL}$ test lipid) PA4 and SA4 effected over $40 \%$ hemolysis
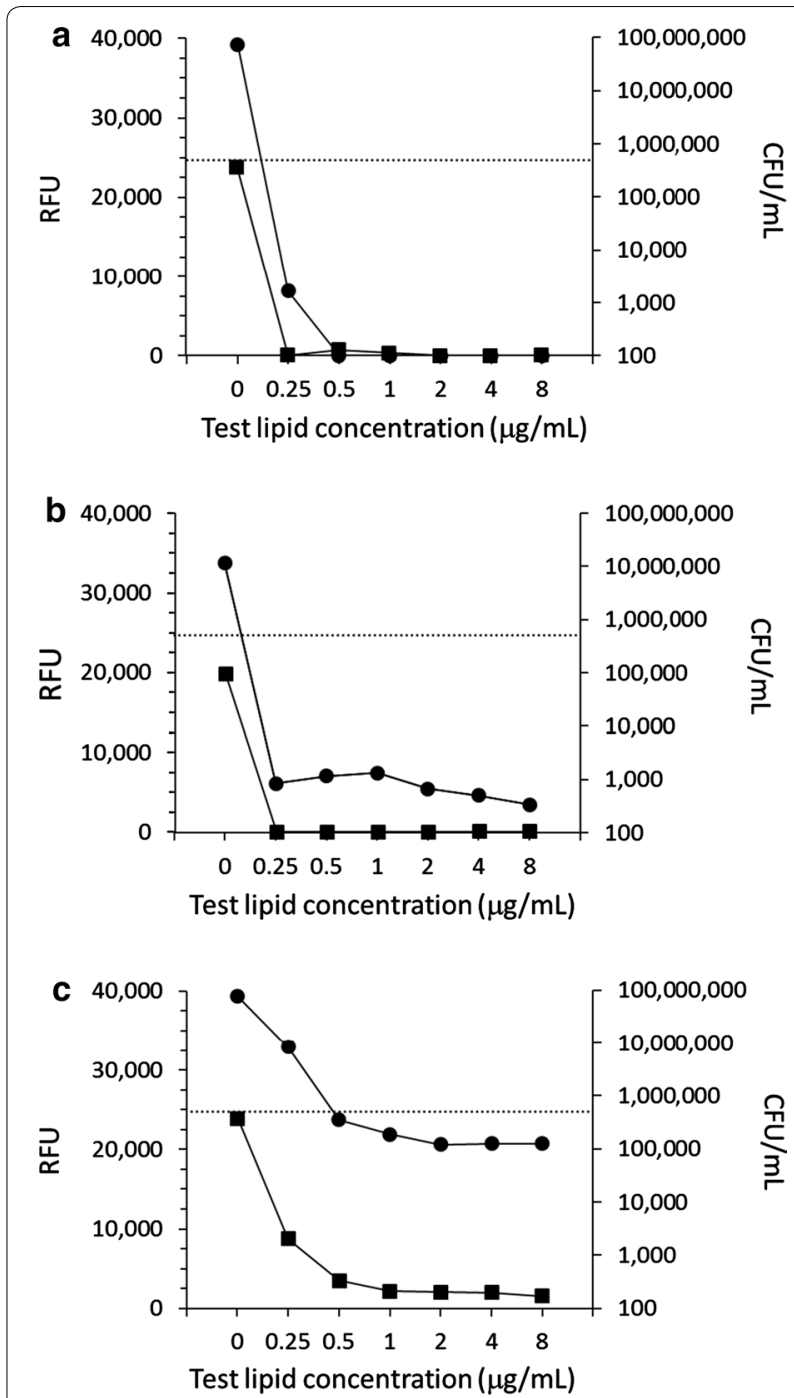

Fig. 1 Minimal bactericidal concentration of liposomal formulations in comparison with their minimal inhibitory concentration. Modified minimal inhibitory concentration (MIC) assay (square symbols, left $y$-axis) was performed with S. epidermidis followed by determination of minimal bactericidal concentration (round symbols, right y-axis). Test lipids were a palmitic acid prepared in carrier-4 (PA4); b stearic acid prepared in carrier 4 (SA4); and c cholesteryl linoleate prepared in carrier-3 (CL3). RFU relative fluorescence units. Dotted line bacterial inoculum (CFU/mL). Shown are means of two experiments conducted in duplicates

within $30 \mathrm{~min}$ and CL3 within $3 \mathrm{~h}$. However, when tested at $90 \mu \mathrm{g} / \mathrm{mL}$ test lipid (between 90 and 360 times the lowest observed MIC) none of the formulations exhibited significant hemolysis over $3 \mathrm{~h}$. Carrier-3 and carrier-4, in the absence of test lipid, also exerted hemolytic effects at the higher dose (both over $40 \%$ hemolysis after $3 \mathrm{~h}$ ), but did not cause hemolysis when tested at $90 \mu \mathrm{g} / \mathrm{mL}$ over $3 \mathrm{~h}$ ( $2.24 \pm 0.6$ and $1.64 \pm 0.2 \%$ hemolysis, respectively). 

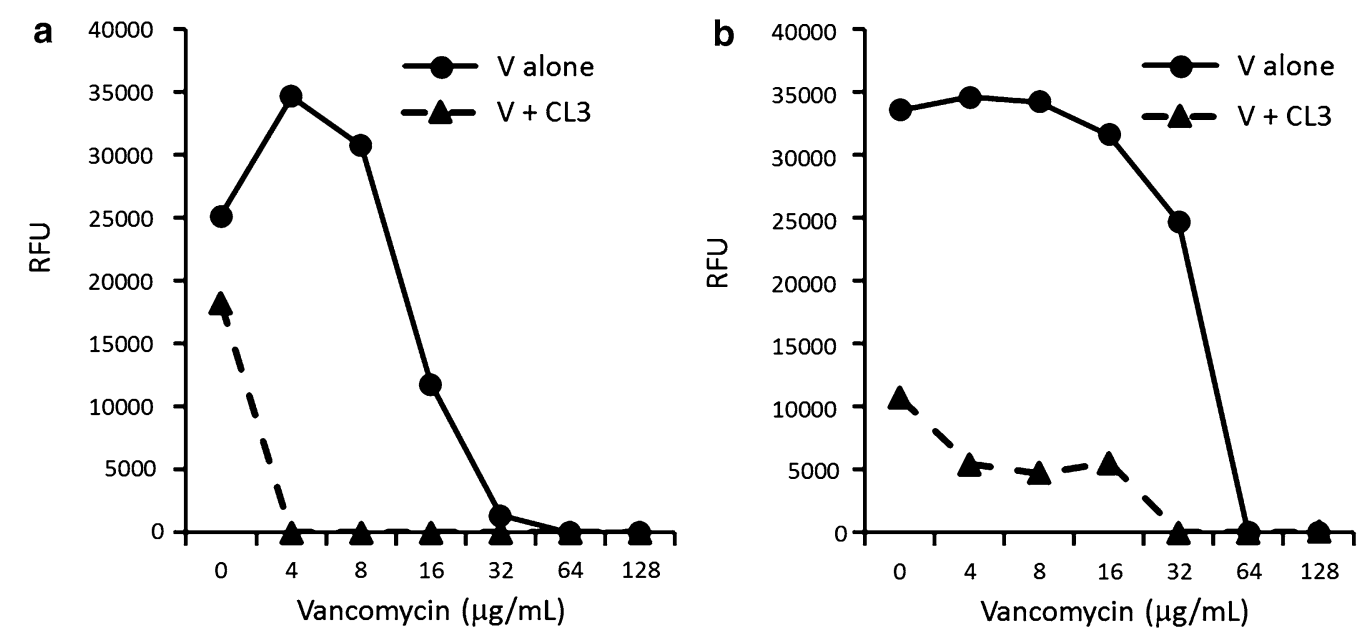

Fig. 2 Minimal inhibitory concentration (MIC) of liposomal cholesteryl linoleate combined with standard antibiotic. Modified MIC assay with Syto 9 fluorescence read out for vancomycin-resistant Enterococcus faecalis incubated with vancomycin (V) in the presence and absence of cholesteryl linoleate prepared in carrier-3 (CL3, $5 \mu \mathrm{g} / \mathrm{mL})$. RFU relative fluorescence units. Shown are averages of triplicate measurements of two independent experiments $(\mathbf{a}, \mathbf{b})$

Table 5 Hemolytic activity of the most potent antimicrobial lipids

\begin{tabular}{|c|c|c|c|c|c|c|}
\hline \multirow[t]{2}{*}{ Liposomal formulation } & \multicolumn{3}{|c|}{ Hemolysis (\% maximal hemolysis) at $900 \mu \mathrm{g} / \mathrm{mL}$} & \multicolumn{3}{|c|}{ At $90 \mu \mathrm{g} / \mathrm{mL}^{\mathrm{a}}$} \\
\hline & $30 \mathrm{~min}$ & $3 \mathrm{~h}$ & $24 \mathrm{~h}$ & $30 \mathrm{~min}$ & $3 \mathrm{~h}$ & $24 \mathrm{~h}$ \\
\hline PA4 & $>40$ & $>40$ & $>40$ & $1.61 \pm 0.50$ & $3.10 \pm 1.00$ & 70.43 \\
\hline SA4 & $>40$ & $>40$ & $>40$ & $2.21 \pm 1.80$ & $4.04 \pm 0.60$ & 46.35 \\
\hline $\mathrm{CL3}$ & $<20$ & $>40$ & $>40$ & $1.13 \pm 0.20$ & $0.80 \pm 0.10$ & 54.55 \\
\hline
\end{tabular}

Hemolysis was screened at $900 \mu \mathrm{g} / \mathrm{mL}$ lipid concentration and further tested at $90 \mu \mathrm{g} / \mathrm{mL}$ lipid concentration (mean \pm S.D., $\mathrm{n}=3$ for $30 \mathrm{~min}$ and $3 \mathrm{~h}$ time points and $\mathrm{n}=1$ for $24 \mathrm{~h}$ time point). PA4 palmitic acid prepared in carrier-4, SA4 stearic acid prepared in carrier-4, CL3 cholesteryl linoleate prepared in carrier-3

a There were no statistically significant differences compared to control erythrocytes after $30 \mathrm{~min}$ and $3 \mathrm{~h}$

Cytotoxic activity was evaluated with HepG2 cells at $100 \mu \mathrm{g} / \mathrm{mL}$ employing the metabolic XTT assay (Fig. 3). While SA4 had significant inhibitory effects, cells treated with PA4 and CL3 were statistically not different from untreated cells. Carrier-3 and carrier-4, when tested alone, also exhibited cytotoxic effects $(40.68 \pm 12.54 \%$ inhibition, $\mathrm{p}<0.05$, and $83.97 \pm 13.88 \%$ inhibition, $\mathrm{p}<0.001$, respectively). This data suggests that the hemolytic and cytotoxic activity of the liposomal formulations is at least in part contributed by the carrier lipid. Considering the varying activities of different lipids incorporated in the same carriers, a complex interaction between the different lipid species is likely.

\section{Discussion}

In this study, striving to address the urgent public health need posed by HAI with multidrug-resistant bacteria, we assessed the potential of free fatty acids and cholesteryl esters as novel antibacterial agents. Liposomes of varying composition were employed as carrier for these lipophilic agents and these formulations were tested against Gram-positive and Gram-negative multidrugresistant bacteria involved in HAI using a modified MIC. The potential for restoring activity of conventional antibiotics was probed and hemolytic and cytotoxic activity assayed. Palmitic and stearic acid as well as cholesteryl linoleate were identified as the most promising compounds whereby the carrier liposome formulation influenced their activity.

To overcome interference of turbidity contributed by liposomes we employed the DNA probe Syto9 to quantify bacterial growth in an otherwise standard MIC assay. Styo 9 has been often used to quantify viable bacteria in biofilms $[26,27]$ but not yet been validated for use in MIC assays, which we did here using quality control strains and standard antibiotics. The modified DNA probe-based MIC assay may also be useful for testing fastidious organisms that require the addition of blood products in their growth media making turbidity based measurements including standard MIC testing obsolete. 


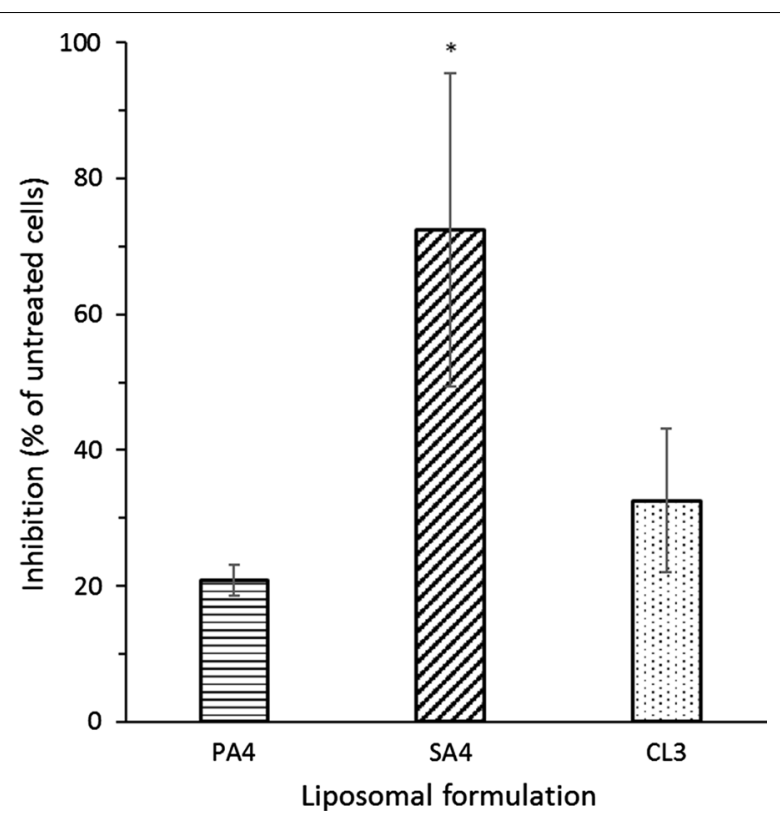

Fig. 3 Cytotoxic activity of the most potent antimicrobial lipids against the cell line HepG2. Metabolically active cells were quantified after $48 \mathrm{~h}$ incubation in the presence and absence of $100 \mu \mathrm{g} / \mathrm{mL}$ test lipid using the XTT assay. PA4 palmitic acid prepared in carrier-4; SA4 stearic acid prepared in carrier-4; CL3 cholesteryl linoleate prepared in carrier-3. Shown are mean \pm S.D., $\mathrm{n}=3 .{ }^{*} p=0.001$ in one-way ANOVA with Bonferroni posthoc analysis

Among the fatty acids and cholesteryl esters tested, palmitic acid, stearic acid, and cholesteryl linoleate emerged as the most active lipids. Palmitic acid and stearic acid acted only against multidrug-resistant S. epidermidis and vancomycin resistant $E$. faecalis, both representing Grampositive cocci. This is in line with an earlier report on the preferential bactericidal activity of fatty acids against Grampositive bacteria [28] though the stated effective concentrations of palmitic acid were substantially higher than what we describe here. The relatively decreased activity reported by Huang et al. [28] may be attributed to the use of ethanol-solubilized fatty acid without a carrier underlining the potential of liposomal formulations to reduce required active concentrations. Cholesteryl linoleate showed activity against the multidrug-resistant $S$. epidermidis and a $P$. aeruginosa strain but was less effective in killing than stearic acid and palmitic acid. This suggests that the cholesteryl ester may have a different mode of action.

We have identified host derived lipids that may have promise for future use as antimicrobials when applied alone or in combination with standard antibiotics. Plant lipids, namely essential oils, have long been used for their antibacterial activity in the food industry [29, 30]. Recently, though, they have been also assessed for clinical use [31, 32], including the use as enhancer of antibiotics [33]. In a rabbit sepsis model, co-administration of the polyunsaturated fatty acids linolenic and arachidonic acid with antibiotics enhanced killing of a multidrug-resistant $P$. aeruginosa strain [34]. Adding lipophilic properties to antimicrobial peptides by $\mathrm{N}$-acylation has also been proven to enhance their antimicrobial activity $[35,36]$.

We observed that the carrier liposome composition influenced the test lipid activity and that some formulation exhibited independent antibacterial activity. This suggests that phospholipid-mediated antimicrobial activity could contribute to the low MIC of palmitic acid and stearic acid. An interaction between the carrier lipids and the test lipids is also implicated by the changes in liposomes size depending on the constituents. Possible mechanisms of the observed liposome activity may include fusion and subsequent disruption of the bacterial cell membrane through lipid embedding into the phospholipid bilayer and, for unsaturated lipids, lipid peroxidation with radical production [15]. Such mechanistic studies are currently under way in our laboratory.

Bacterial and mammalian cell membranes both are composed of phospholipid bilayers. Thus, it is conceivable that the antibacterial liposome formulations exhibit hemolytic and cytotoxic activity against mammalian cells. At concentrations ninety times or higher than the lowest MIC no hemolytic activity was observed within the first $3 \mathrm{~h}$ but prolonged incubation resulted in hemolysis. This suggests that topical use may be a preferable treatment strategy for liposomal lipids. Cytotoxic effects through lipid peroxidation and mitochondria-initiated apoptosis have been well documented, in particular for unsaturated fatty acids such as linoleic acid [37, 38], and cytotoxic fatty acids are under investigation for intended use in cancer treatment $[39,40]$. Here, we found that palmitic acid and cholesteryl linoleate did not cause significant growth inhibition of HepG2 cells but that stearic acid displayed significant cytotoxicity. Considering that the degree of antibacterial activity was influenced by the carrier composition and that the carriers also exerted some hemolytic and cytotoxic effects, careful selection and modification of the carrier lipids may yield antimicrobial formulations devoid of hemolytic and cytotoxic activity.

Liposomes have been previously used as carrier for antimicrobial compounds. For example, the antifungal drug amphotericin B was successfully formulated in liposomes with greatly reduced cytotoxicity [41]. Other applications include liposomal delivery of antibiotics to pathogens entrapped in biofilms and intracellular pathogens $[42,43]$. A major advantage of using liposomes as carrier for antimicrobial lipids (and other compounds) is the possibility to insert molecules that enable targeted delivery of the drug [44]. 


\section{Conclusions}

In summary, our results showed that selected fatty acids and cholesteryl esters packaged with phospholipids exhibit antibacterial activity against Gram-positive and Gram-negative bacterial species and may augment the activity of antibiotics. Bactericidal activity could be unlinked from hemolytic and cytotoxic activity. The type of phospholipid carrier greatly influenced the activity. Thus, fatty acids and cholesteryl esters may have potential as novel lipophilic antimicrobial agents whereby modulating the phospholipid composition and incorporating tags may enable targeting specific types of bacteria.

\section{Additional file}

Additional file 1: Table S1. Test lipid composition and particle size.

\section{Abbreviations}

CFU: colony forming units; $\mathrm{CL}$ : cholesteryl linoleate; HAl: healthcare associated infections; MBC: minimal bactericidal concentration; MDR: multidrug resistant; MIC: minimal inhibitory concentration; PA: palmitic acid; RBC: red blood cell; RFU: relative fluorescence unit; SA: stearic acid; XTT: 2,3-Bis-(2-Methoxy-4-Nitro-5-Sulfophenyl)-2H-Tetrazolium-5-Carboxanilide.

\section{Authors' contributions}

AHC conducted all modified MIC and MBC assays; drafted manuscript, revised and approved the final manuscript. NS performed MIC validation, revised and approved the final manuscript. RW conducted vancomycin synergism experiments, revised and approved the final manuscript. JG performed cytotoxicity testing, revised and approved the final manuscript. TQD, WE, and SMC designed and produced liposomes, revised and approved the final manuscript. SK performed hemolysis assays, revised and approved the final manuscript. HHX and GF participated in study design, revised and approved the final manuscript. EP designed the study, coordinated all experiments and communicated with all participants, co-wrote the manuscript and revised. All authors read and approved the final manuscript.

\section{Author details}

1 Department of Biological Sciences, California State University Los Angeles, 5151 State University Drive, Los Angeles, CA 90032, USA. ${ }^{2}$ Molecular Express, Inc., Rancho Dominguez, CA, USA.

\section{Acknowledgements}

We thank Yessenia Velazco for technical assistance and Dr. Susan Kane for advice on cytotoxicity testing.

\section{Competing interests}

The authors declare that they have no competing interests.

\section{Availability of data and materials}

All data are shown in the manuscript.

\section{Funding}

NIH Grants 1SC1GM096916, 1P20CA118783-01A1, 1P20CA118775-01A 1P20MD001824, and MBRS RISE R25 GM61331; Army Research Office W911NF-12-1-0059; CSUPERB Entrepreneurial Joint Venture Matching Grant Program.

Received: 22 March 2016 Accepted: 28 June 2016

Published online: 08 July 2016
References

1. Tangden T, Giske CG. Global dissemination of extensively drug-resistant carbapenemase-producing Enterobacteriaceae: clinical perspectives on detection, treatment and infection control. J Intern Med. 2015:277:501-12.

2. Sievert DM, Ricks P, Edwards JR, Schneider A, Patel J, Srinivasan A, Kallen A, Limbago B, Fridkin S, Network National Healthcare Safety, et al. Antimicrobial-resistant pathogens associated with healthcare-associated infections: summary of data reported to the National Healthcare Safety Network at the Centers for Disease Control and Prevention, 2009-2010. Infect Control Hosp Epidemiol. 2013;34:1-14.

3. Magill SS, Edwards JR, Bamberg W, Beldavs ZG, Dumyati G, Kainer MA, Lynfield R, Maloney M, McAllister-Hollod L, Nadle J, et al. Multistate pointprevalence survey of health care-associated infections. N Engl J Med. 2014;370:1198-208.

4. Centers for disease control and prevention. 2013 National and state healthcare-associated infections progress report. Published January 14, 2015. www.cdc.gov/hai/progress-report/index.html. 2015.

5. Harbarth S, Theuretzbacher U, Hackett J, consortium DA. Antibiotic research and development: business as usual. J Antimicrob Chemother. 2015;70:1604-7.

6. Theuretzbacher U. Recent FDA antibiotic approvals: good news and bad news. In: The center for disease dynamics, economics \& policy, vol. 12 Washington DC 2015

7. Lewis K. Platforms for antibiotic discovery. Nat Rev Drug Discov 2013;12:371-87.

8. Eckert R. Road to clinical efficacy: challenges and novel strategies for antimicrobial peptide development. Future Microbiol. 2011;6:635-51.

9. Tavares LS, Silva CS, de Souza VC, da Silva VL, Diniz CG, Santos MO. Strategies and molecular tools to fight antimicrobial resistance: resistome, transcriptome, and antimicrobial peptides. Front Microbiol. 2013;4:412.

10. Xu HH, Trawick JD, Haselbeck RJ, Forsyth RA, Yamamoto RT, Archer R, Patterson J, Allen M, Froelich JM, Taylor I, et al. Staphylococcus aureus targetarray: comprehensive differential essential gene expression as a mechanistic tool to profile antibacterials. Antimicrob Agents Chemother. 2010;54:3659-70

11. Ling LL, Schneider T, Peoples AJ, Spoering AL, Engels I, Conlon BP, Mueller A, Schaberle TF, Hughes DE, Epstein S, et al. A new antibiotic kills pathogens without detectable resistance. Nature. 2015;517:455-9.

12. Porter E, Ma DC, Alvarez S, Faull KF. Antimicrobial lipids: emerging effector molecules of innate host defense. World J Immunol. 2015;5:51-61.

13. Lipids and essential oils as antimicrobial agents. Chichester: Wiley; 2011.

14. Fahy E, Subramaniam S, Brown HA, Glass CK, Merrill AH Jr, Murphy RC, Raetz CR, Russell DW, Seyama Y, Shaw W, et al. A comprehensive classification system for lipids. J Lipid Res. 2005;46:839-61.

15. Desbois AP, Smith VJ. Antibacterial free fatty acids: activities, mechanisms of action and biotechnological potential. Appl Microbiol Biotechnol. 2010;85:1629-42

16. Do TQ, Moshkani S, Castillo P, Anunta S, Pogosyan A, Cheung A, Marbois B, Faull KF, Ernst W, Chiang SM, et al. Lipids including cholesteryl linoleate and cholesteryl arachidonate contribute to the inherent antibacterial activity of human nasal fluid. J Immunol. 2008;181:4177-87.

17. Fujii G, Chang JE, Coley T, Steere B. The formation of amphotericin B ion channels in lipid bilayers. Biochemistry. 1997;36:4959-68.

18. Proffitt RT, Satorius A, Chiang SM, Sullivan L, Adlermoore JP. Pharmacology and toxicology of a liposomal formulation of amphotericin B (AmBisome) in rodents. J Antimicrob Chemother. 1991;28(Suppl B):49-61.

19. Kohli AG, Kierstead PH, Venditto VJ, Walsh CL, Szoka FC. Designer lipids for drug delivery: from heads to tails. J Control Release. 2014;190:274-87.

20. Noble GT, Stefanick JF, Ashley JD, Kiziltepe T, Bilgicer B. Ligand-targeted liposome design: challenges and fundamental considerations. Trends Biotechnol. 2014;32:32-45.

21. Ernst WA, Kim HJ, Tumpey TM, Jansen AD, Tai W, Cramer DV, Adler-Moore JP, Fujii G. Protection against $\mathrm{H} 1, \mathrm{H} 5, \mathrm{H} 6$ and $\mathrm{H} 9$ influenza $\mathrm{A}$ infection with liposomal matrix 2 epitope vaccines. Vaccine. 2006;24:5158-68.

22. CLSI. Methods for dilution antimicrobial susceptibility tests for bacteria that grow aerobically; Approved standard-ninth edition. CLSI document M07-A19. In: Wayne PA. Clinical and Laboratory Standards Institute; 2012. 
23. CLSI. M26-A: Methods for determining bactericidal activity of antimicrobial agents; Approved Guideline. In: Wayne PA. Clinical Laboratory Standards Institute; 1999.

24. Zander R, Lang W, Wolf HU. Alkaline haematin D-575, a new tool for the determination of haemoglobin as an alternative to the cyanhaemiglobin method. I. Description of the method. Clin Chim Acta. 1984;136:83-93.

25. Tew GN, Clements D, Tang H, Arnt L, Scott RW. Antimicrobial activity of an abiotic host defense peptide mimic. Biochim Biophys Acta. 2006;1758:1387-92.

26. Cao B, Christophersen L, Thomsen $K$, Sonderholm M, Bjarnsholt T, Jensen $\mathrm{PO}$, Hoiby N, Moser C. Antibiotic penetration and bacterial killing in a Pseudomonas aeruginosa biofilm model. J Antimicrob Chemother. 2015;70:2057-63.

27. Peeters E, Nelis HJ, Coenye T. Comparison of multiple methods for quantification of microbial biofilms grown in microtiter plates. J Microbiol Methods. 2008;72:157-65.

28. Huang CB, Alimova Y, Myers TM, Ebersole JL. Short- and medium-chain fatty acids exhibit antimicrobial activity for oral microorganisms. Arch Oral Biol. 2011;56:650-4.

29. Seow $Y X$, Yeo CR, Chung HL, Yuk HG. Plant essential oils as active antimicrobial agents. Crit Rev Food Sci Nutr. 2014;54:625-44.

30. Juneja VK, Dwivedi HP, Yan X. Novel natural food antimicrobials. Annu Rev Food Sci Technol. 2012;3:381-403.

31. Mantle D, Gok MA, Lennard TW. Adverse and beneficial effects of plant extracts on skin and skin disorders. Adverse Drug React Toxicol Rev. 2001:20:89-103.

32. Martin KW, Ernst E. Herbal medicines for treatment of bacterial infections: a review of controlled clinical trials. J Antimicrob Chemother. 2003;51:241-6.

33. Langeveld WT, Veldhuizen EJ, Burt SA. Synergy between essential oil components and antibiotics: a review. Crit Rev Microbiol. 2014;40:76-94.

34. Giamarellos-Bourboulis EJ, Mouktaroudi M, Adamis T, Koussoulas V, Baziaka F, Perrea D, Karayannacos PE, Giamarellou H. n-6 polyunsaturated fatty acids enhance the activities of ceftazidime and amikacin in experimental sepsis caused by multidrug-resistant Pseudomonas aeruginosa. Antimicrob Agents Chemother. 2004;48:4713-7.
35. Joshi S, Dewangan RP, Yadav S, Rawat DS, Pasha S. Synthesis, antibacterial activity and mode of action of novel linoleic acid-dipeptide-spermidine conjugates. Org Biomol Chem. 2012;10:8326-35.

36. Zweytick D, Deutsch G, Andra J, Blondelle SE, Vollmer E, Jerala R, Lohner K. Studies on lactoferricin-derived Escherichia coli membrane-active peptides reveal differences in the mechanism of $\mathrm{N}$-acylated versus nonacylated peptides. J Biol Chem. 2011;286:21266-76.

37. Rial E, Rodriguez-Sanchez L, Gallardo-Vara E, Zaragoza P, Moyano E, Gonzalez-Barroso MM. Lipotoxicity, fatty acid uncoupling and mitochondrial carrier function. Biochim Biophys Acta. 2010;1797:800-6.

38. Das UN. Essential fatty acids, lipid peroxidation and apoptosis. Prostaglandins Leukot Essent Fatty Acids. 1999;61:157-63.

39. Murray M, Hraiki A, Bebawy M, Pazderka C, Rawling T. Anti-tumor activities of lipids and lipid analogues and their development as potential anticancer drugs. Pharmacol Ther. 2015;150:109-28.

40. Fauser JK, Prisciandaro LD, Cummins AG, Howarth GS. Fatty acids as potential adjunctive colorectal chemotherapeutic agents. Cancer Biol Ther. 2011;11:724-31.

41. Adler-Moore J, Proffitt RT. Am Bisome: liposomal formulation, structure, mechanism of action and pre-clinical experience. J Antimicrob Chemother. 2002;49(Suppl 1):21-30.

42. Forier K, Raemdonck K, De Smedt SC, Demeester J, Coenye T, Braeckmans K. Lipid and polymer nanoparticles for drug delivery to bacterial biofilms. J Control Release. 2014;190:607-23.

43. Abed N, Couvreur P. Nanocarriers for antibiotics: a promising solution to treat intracellular bacterial infections. Int J Antimicrob Agents. 2014:43:485-96.

44. Allen TM, Cullis PR. Liposomal drug delivery systems: from concept to clinical applications. Adv Drug Deliv Rev. 2013;65:36-48.

\section{Submit your next manuscript to BioMed Central and we will help you at every step:}

- We accept pre-submission inquiries

- Our selector tool helps you to find the most relevant journal

- We provide round the clock customer support

- Convenient online submission

- Thorough peer review

- Inclusion in PubMed and all major indexing services

- Maximum visibility for your research

Submit your manuscript at www.biomedcentral.com/submit
() Biomed Central 